\title{
Fulminant Hepatic Failure without Evidence of Cirrhosis in a Case of Wilson's Disease
}

\author{
Katsuaki ENOMOTO, Hiromi ISHIBASHI, Katsumi IRIE, Yuzo OKUMURA, \\ Hideyuki Nomura, Masahiro FUKUSHIMA*, Shoichi INABA** and Yoshiyuki NiHO
}

\begin{abstract}
We treated a sixteen-year old Japanese girl with fulminant hepatic failure in Wilson's disease. The diagnosis of Wilson's disease was made immediately after the admission because of low serum copper and ceruloplasmin levels with high urinary copper excretion. Her hepatic failure was accompanied by bouts of hemolytic crisis. In spite of the administration of D-penicillamine and repeated plasmapheresis, she died of hepatic failure four months later. At autopsy, the surface of the liver was smooth. The histology of the liver showed massive necrosis. There were only a few remaining scattered hepatocytes, in which copper was revealed by Rhodanine staining. There was no evidence of cirrhosis. The livers of the previously reported cases of Wilson's disease accompanied by fulminant hepatic failure were all cirrhotic. Our case indicated that Wilson's disease could occur as true fulminant hepatic failure without preceeding neurological and hepatological signs and the evidence of cirrhosis.
\end{abstract}

Key words: Wilson's disease, Hepatolenticular degeneration, Fulminant hepatic failure, Hemolytic anemia.

Hepatolenticular disease, or Wilson's disease, was initially described as a progressive cerebral degeneration by Wilson (1) in 1912. In the classic form of Wilson's disease, neurological manifestations are dominant and are often accompanied by KayserFleischer corneal ring and renal dysfunction. In the pediatric age group, however, liver dysfunction may often be an initial symptom (2). Hepatic lesions vary from non-specific changes to cirrhosis. Recently, a number of cases of Wilson's disease presenting as fulminant hepatic failure have been reported. However, fulminant hepatic failure is still a rare occurence in Wilson's disease. Moreover, in most cases published so far, the diagnosis of acute Wilson's disease was made at the postmortem examination.
We report here concerning a sixteen-year-old Japanese girl of Wilson's disease which took a course resembling fulminant hepatic failure. The diagnosis was made within one week after admission and an extensive therapy including plasmapheresis and D-penicillamine administration was performed, however, she died of hepatic failure. Although the livers of previously reported patients of Wilson's disease associated with fulminant hepatic failure were all cirrhotic, the liver of our patient was not found to be cirrhotic.

\section{CASE REPORT}

A sixteen-year-old Japanese girl developed abdominal distension, pretibial edema and jaundice and was admitted to a local hospital. She was a high-

From The First Department of Internal Medicine, *Department of Pathology, Faculty of Medicine, Kyushu University and **Blood Transfusion Service, Kyushu University Hospital, Fukuoka 812, Japan

Received for publication May 20, 1988.

Reprint request to: Hiromi Ishibashi, MD, The First Department of Internal Medicine, Faculty of Medicine, Kyushu University, Higashi-ku, Fukuoka 812, Japan 
school student and had been playing volleyball until six days before the admission as a member of a volleyball team. Thirteen days later she was moved to Kyushu University Hospital. On admission the patient was alert. A physical examination revealed slight anemia and jaundice. The abdomen was distended and an elastic firm liver edge was palpable $3 \mathrm{~cm}$ below the right costal margin. Edema was present in the pretibial region. The neurological examination revealed no abnormal findings.

Laboratory findings were as follows: hemoglobin concentration, $10.6 \mathrm{~g} / \mathrm{dl}$; hematocrit, $33.0 \%$; white blood cell count, $8900 / \mathrm{cu} \mathrm{mm}(60 \%$ segmented polymorphonuclear, $10 \%$ band, $1 \%$ eosinophils, $2 \%$ basophils, $24 \%$ lymphocytes, and $3 \%$ monocytes); platelet count, $241,000 / \mathrm{cu} \mathrm{mm}$; prothrombin time, 20.1 seconds (28\%); PTT, 46.2 seconds; hepaplastin test $19 \%$; total bilirubin, 2.6 mg/dl; SGOT 177 IU/l; SGPT 107 IU/l; total protein, $6.8 \mathrm{~g} / \mathrm{dl}$; albumin, $2.2 \mathrm{~g} / \mathrm{dl}$; Coomb's test was negative. HbsAg and other anti-viral antibodies were negative. Urinalysis showed a trace amount of protein and positive for bilirubin. Ultrasonic study of the abdomen revealed mild hepatomegaly with a slightly irregular parenchymal echo pattern, splenomegaly and a moderate volume of ascites. Electroencephalography showed slow waves. Serum ceruloplasmin $(4.5 \mathrm{mg} / \mathrm{dl})$ and serum copper (56 $\mu \mathrm{g} / \mathrm{dl})$ levels were low, whereas urinary copper excretion was markedly increased (2780 $\mu \mathrm{g} /$ day)

From these laboratory data the diagnosis of Wilson's disease was made within one week after the admission. In addition to the therapy for the hepatic failure, administration of D-penicillamine was started. Though urinary copper excretion increased, hepatic failure progressively worsened. On the 42th hospital day, a bout of hemolytic anemia occurred; the hemoglobin fell from 8.7 to $5.6 \mathrm{~g} / \mathrm{dl}$, the total bilirubin level increased from 5.0 to 19.8 $\mathrm{mg} / \mathrm{dl}$, serum copper level raised from 79 to 139 $\mu \mathrm{g} / \mathrm{dl}$ and urinary copper excretion from 4,000 to $10,500 \mu \mathrm{g} /$ day. Through treatments with plasmapheresis and blood transfusions, anemia and jaundice were improved. However, hepatic failure was gradually advanced. Two months later she developed consciousness disturbance and died of hepatic failure four months later.

At autopsy, the patient was markedly icteric. The

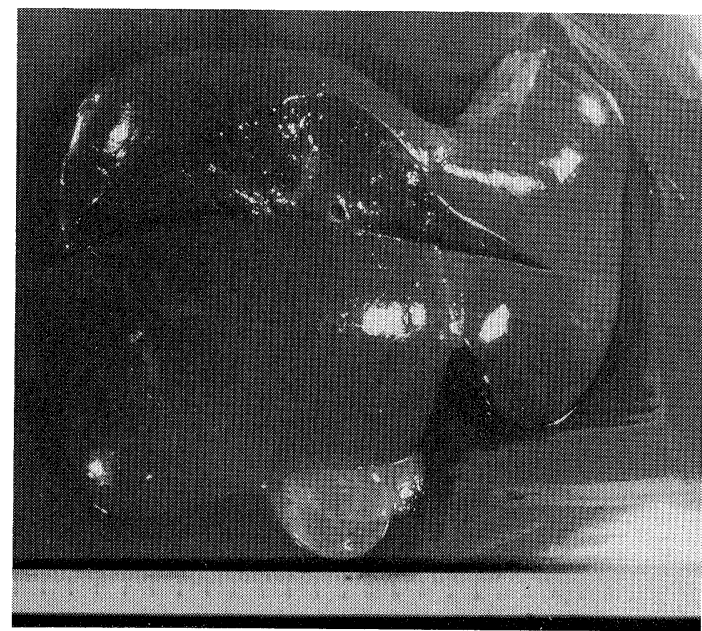

Fig. 1. Gross appearance of the atrophic liver $(950 \mathrm{~g})$ showing a smooth surface.

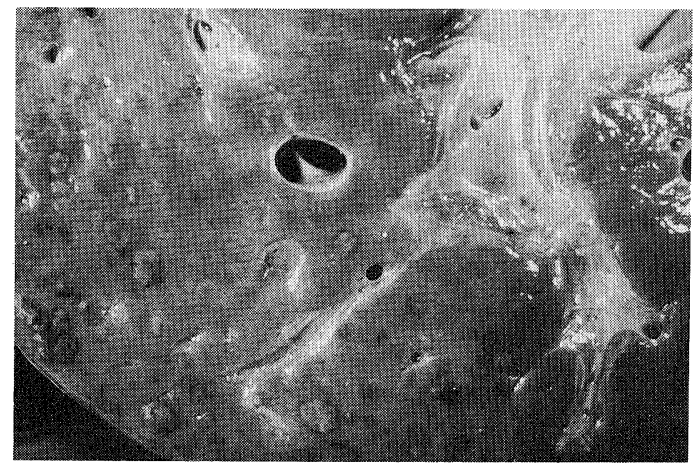

Fig. 2. Cross section of the liver showing scattered small nodules of necrotic cells.

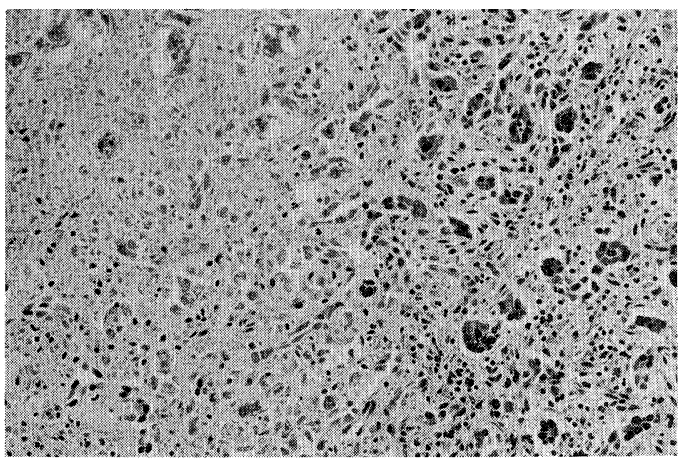

Fig. 3. Histology of the liver showing massive necrosis with several scattered residual hepatocytes and poorly developed fibrosis (Masson Trichrome staining, $\times 100$ ).

liver was atrophic $(950 \mathrm{~g})$ but the surface was smooth and no nodules were seen (Fig. 1). An incision of 


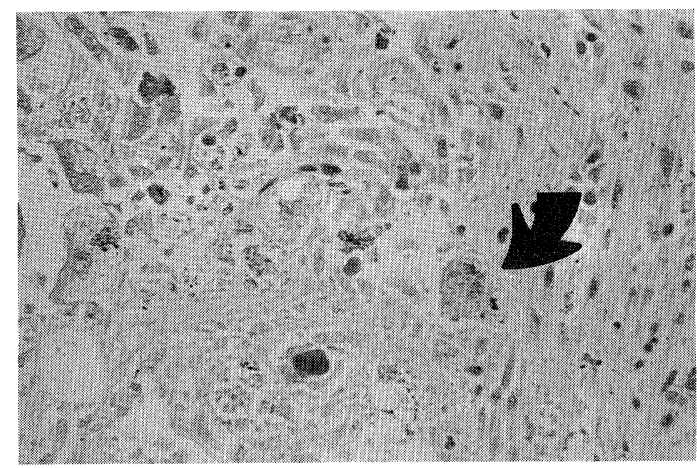

Fig. 4. Rhodanine staining of the liver histology. Copper depotion was seen in the residual hepatocytes $(\times 200)$.

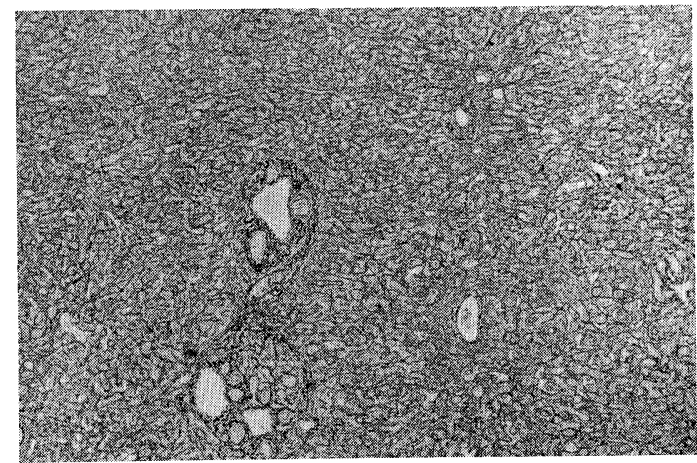

Fig. 5. Silver staining of the liver histology. The architecture of the reticulin fibers is almost preserved and pseudolobular formation is not seen $(\times 50)$.

the surface of the liver disclosed disarrangement of the lobular architecture (Fig. 2). Several small, scattered nodules of greyish-yellow color were disclosed by microscopic examination as necrotic cells. The spleen was enlarged $(600 \mathrm{~g})$. The right kidney had infarction, and the left kidney was compensatorily hypertrophic. Microscopically, the liver showed massive necrosis (Fig. 3). Rhodanine staining showed copper deposition in the residual hepatocytes (Fig. 4). Fibrosis was scarcely seen and no cirrhosis was found (Fig. 5).

\section{DISCUSSION}

The hepatic manifestation of Wilson's disease vary greatly and have been described as acute hepatitis, chronic active hepatitis or cirrhosis (3). Since the report by Roche-Sicot and Benhamou (4) in 1977, there have been several reports of the acute onset of Wilson's disease resembling fulminant hepatic failure. Table 1 summarized 20 cases of Wilson's disease which were reported as being fulminant hepatic failure-connected (2-14). Patient ages were between 8 and 22 years old (average 15.5 years old). Seven were males and 14 females. Neurological signs were positive in 8 of 20 cases and KayserFleischer rings in 9 of 16 cases. Serum copper levels were elevated in 12 of 18 cases and urinary copper excretion had increased in all 16 cases, while serum ceruloplasmin levels were low in 10 of 16 cases. Copper content in the liver increased to more than $250 \mathrm{~g} / \mathrm{g}$ dry weight in 11 of 13 cases. Hemolytic anemia was demonstrated in all of 18 described cases.

Characteristic of acute hepatic failure in Wilson's disease is concomitance of acute intravascular hemolytic anemia. The hematological and biochemical data support the characteristic: 1) higher copper levels in serum, urine and liver; 2) less pronounced elevations of transaminase levels; 3 ) higher concentrations of total bilirubin; and 4) lower hemoglobin values (15). These four biochemical findings were present in all reported cases including ours.

The mechanism of acute hepatic failure in Wilson's disease is still speculative. According to Deiss et al. (16), a progressive accumulation of copper occuring in the hepatic cell results in Wilson's disease. The redistribution of the metal from the cytoplasm to the lysosomes takes place slowly in most patients and has no clinical consequences. Patients, in whom copper redistribution occurs suddenly, resulting in the necrosis of liver cells, often show hepatic failure. The subsequent release of copper from the necrotic liver cells causes hemolytic anemia.

Livers of the previously reported 20 cases were all cirrhotic. In our case, however, there was no evidence of cirrhosis macroscopically or even microscopically. Since the patient had been a member of a high school volleyball team and had been exercising very hard, her liver may have become rapidly aggravated after the onset of the disease but before the liver became cirrhotic.

Since the clinical disease course is very rapid and is accompanied by hemolytic anemia, the diagnosis of fulminant hepatic failure in Wilson's disease is 
Table 1. Clinical findings of 20 reported cases with Wilson's disease who developed fulminant hepatic failure

\begin{tabular}{|c|c|c|c|c|c|c|c|c|c|c|c|c|c|c|}
\hline $\begin{array}{l}\text { Case } \\
\text { No }\end{array}$ & $\begin{array}{c}\text { Age } \\
\text { (y. }\end{array}$ & $\begin{array}{l}\text { Sex } \\
\text { o.) }\end{array}$ & $\begin{array}{l}\text { Neurological } \\
\text { findings } \\
\text { on admission }\end{array}$ & $\begin{array}{l}\text { Hemolytic } \\
\text { anemia }\end{array}$ & $\begin{array}{l}\text { Kayser- } \\
\text { Fleischer } \\
\text { rings }\end{array}$ & $\begin{array}{l}\text { SGOT } \\
\text { (SGPT) } \\
\text { U/L }\end{array}$ & $\begin{array}{l}\text { T. Bil. } \\
\mathrm{mg} / \mathrm{di}\end{array}$ & $\begin{array}{l}\mathrm{PT} \\
\text { sec. } \\
(\%)\end{array}$ & $\begin{array}{c}\text { Serum } \\
\mathrm{Cu} \\
\mu \mathrm{g} / \mathrm{dl}\end{array}$ & $\begin{array}{c}\text { Urinary } \\
\mathrm{Cu} \\
\mu \mathrm{g} / \mathrm{day}\end{array}$ & $\begin{array}{l}\text { Cerulo- } \\
\text { plasmin } \\
\mathrm{mg} / \mathrm{dl}\end{array}$ & $\begin{array}{c}\text { Liver } \\
\text { Cu } \\
\mu \mathrm{g} / \mathrm{g} \text { dry } \\
\text { weight } \\
\text { (wet weight) }\end{array}$ & Cirrhosis & Reference \\
\hline 1 & 12 & M & - & n.d.* & + & n.d. & 0.6 & (21) & n.d. & 500 & n.d. & n.d. & + & 3 \\
\hline 2 & 13 & $\mathrm{~F}$ & - & + & - & 100 & 59.3 & (22) & 73 & 910 & 12 & n.d. & + & 2 \\
\hline 3 & 8 & $\mathrm{~F}$ & - & + & n.d. & (45) & 7.5 & (19) & 164 & 4800 & 9 & n.d. & + & 4 \\
\hline 4 & 13 & M & - & + & n.d. & $(80)$ & 8.0 & (10) & 233 & 3600 & 8 & n.d. & + & 4 \\
\hline 5 & 15 & $\mathrm{~F}$ & - & + & n.d. & (60) & 11.0 & (20) & 280 & 1600 & 2 & n.d. & + & 4 \\
\hline 6 & 10 & M & + & n.d. & n.d. & 425 & 50.4 & 50 & n.d. & n.d. & 11 & (189) & + & 5 \\
\hline 7 & 12 & $\mathrm{~F}$ & + & + & + & 190 & 63.2 & 36 & 211 & anuric & n.d. & 550 & + & 6 \\
\hline 8 & 17 & $\mathrm{~F}$ & + & + & + & 85 & 32.7 & n.d. & 288 & 780 & 25 & 444 & + & 6 \\
\hline 9 & 17 & $\mathrm{~F}$ & - & + & + & 85 & 2.3 & 19 & 80 & 2288 & n.d. & 683 & + & 7 \\
\hline 10 & 9 & M & - & + & + & n.d. & n.d. & n.d. & WNL & $\uparrow$ & WNL & $>250$ & + & 8 \\
\hline 11 & 9 & M & - & + & - & n.d. & n.d. & n.d. & WNL & $\uparrow$ & WNL & $>250$ & + & 8 \\
\hline 12 & 16 & $\mathrm{~F}$ & - & + & - & n.d. & n.d. & n.d. & $\downarrow$ & $\uparrow$ & $\downarrow$ & $>250$ & + & 8 \\
\hline 13 & 17 & $\mathrm{~F}$ & - & + & + & n.d. & n.d. & n.d. & WNL & $\uparrow$ & WNL & $>250$ & + & 8 \\
\hline 14 & 18 & $\mathrm{~F}$ & - & + & + & 66 & 40.2 & (10) & 260 & 3012 & 16 & 412 & + & 9 \\
\hline 15 & 21 & $\mathrm{~F}$ & + & + & - & 99 & 43.5 & 41.2 & 222 & 1280 & 27.1 & 1390 & + & 10 \\
\hline 16 & 11 & M & + & + & + & 146 & 54.2 & 27.3 & 376 & n.d. & 0.12 & 1346 & + & 11 \\
\hline 17 & 22 & $\mathrm{~F}$ & + & + & + & 257 & 73.1 & 37.0 & 354 & n.d. & 25 & 786 & + & 12 \\
\hline 18 & 20 & M & - & + & - & 156 & 56.6 & n.d. & 262 & 11600 & n.d. & 188 & + & 13 \\
\hline 19 & 21 & $\mathrm{~F}$ & + & + & n.d. & n.d. & 70.0 & n.d. & n.d. & n.d. & n.d. & n.d. & + & 14 \\
\hline 20 & 19 & $\mathrm{~F}$ & + & + & - & 46.7 & 5.1 & n.d. & 88 & 1300 & 8.3 & n.d. & + & 14 \\
\hline $21^{* *}$ & 16 & $\mathrm{~F}$ & - & + & - & 177 & 2.6 & 20.1 & 56 & 2780 & 4.5 & 142.5 & - & \\
\hline
\end{tabular}

WNL: within normal limits.

extremely difficult. In our case, the diagnosis was made within one week and D-penicillamine therapy was subsequently instituted. However, the hepatic failure progressed rapidly in spite of intensive therapies including repeated plasmapheresis. Since the clinical courses of the reported cases were also very rapid the diagnosis of Wilson's disease must be established early before the onset of acute symptoms and the specific therapy by D-penicillamine should be initiated as early as possible.

\section{REFERENCES}

1) Wilson SAK: Progressive lenticular degeneration: Familial nervous disease associated with cirrhosis of liver. Brain 34: 295, 1912.

2) Slovis TL, Dubois RS, Rodgerson DO et al: The varied manifestations of Wilson's disease. J Pediatr 78: 578, 1971.

3) Lawrie NR and Carter RA: Acute case of Wilson's disease. Lancet 1: 1309, 1958.

4) Roche-Sicot J and Benhamou JP: Acute intravascular hemolysis and acute liver failure associated as a first manifestation of Wilson's disease. Ann Intern Med 86: 301, 1977.
5) Adler R, Mahnovski V, Heuser ET, et al: Fulminant hepatitis: A presentation of Wilson's disease. Am J Dis Child 131: 870, 1977.

6) Hamlyn AN, Gollan JL, Douglas AP, et al: Fulminant Wilson's disease with hemolysis and renal failure: Copper studies and assessment of dialysis regimens. $\mathrm{Br}$ Med J 2: 660, 1977.

7) Doering EJ, Savage RA and Dittmer TE: Hemolysis, coagulation defects, and fulminant hepatic failure as a presentation of Wilson's disease. Am J Dis Child 133: 440, 1979.

8) Scott J, Gollan JL, Samourian S, et al: Wilson's disease presenting as chronic active hepatitis. Gastroenterology 78: 803, 1980.

9) Vielhauer W, Eckardt V, Holtermüller $\mathrm{KH}$, et al: Dpenicillamine in Wilson's disease presenting as acute liver failure with hemolysis. Dig Dis Sci 27: 1126, 1982.

10) McCullough AJ, Wiesner RH, Fleming $\mathrm{CR}$, et al: Antemortem diagnosis and short-term survival of a patient with Wilson's disease presenting as fulminant hepatic failure. Dig Dis Sci 29: 862, 1984.

11) Kraut JR and Yogev R: Fatal fulminant hepatitis with hemolysis in Wilson's disease, criteria for diagnosis. Clin Pediatr 23: 637, 1984.

12) Rakela J, Kurtz SB, McCarthy JT, et al: Fulminant Wilson's disease treated with postdilution hemofiltration and orthotopic liver transplantation. Gastro- 
enterology 90: 2004, 1986.

13) Wilson RA, Clayson KJ and Leon S: Unmeasurable serum alkaline phosphatase activity in Wilson's disease associated with fulminant hepatic failure and hemolysis. Hepatology 7: 613, 1987.

14) Hartleb M, Zahorska-Markiewicz B and Ciesielski A: Wilson's disease presenting in sisters as fulminant hepatitis with hemolytic episodes. Am J Gastroenterol 82: 549, 1987.

15) McCullough AJ, Fleming CR, Thistle JL, et al: Diagnosis of Wilson's disease presenting as fulminant hepatic failure. Gastroenterology 84: 161, 1983.

16. Deiss A, Lee GR and Cartwright GE: Hemolytic anemia in Wilson's disease. Ann Intern Med 73: 413, 1970. 